\title{
Ruthenium(III)-Catalyzed Oxidation of Vanillin by Anticancer Hexachloroplatinate(IV) Complex in Perchloric Acid Solutions: A Kinetic Study
}

\author{
Ahmed Fawzy ${ }^{1,2}$, Ishaq A. Zaafarany ${ }^{1}$, Khalid S. Khairou ${ }^{1}$, Layla S. Almazroai ${ }^{1}$, \\ Badriah A. Al-Jahdali ${ }^{1}$, Tahani M. Bawazeer ${ }^{1}$ \\ ${ }^{1}$ Chemistry Department, Faculty of Applied Science, Umm Al-Qura University, Makkah, Saudi Arabia \\ ${ }^{2}$ Chemistry Department, Faculty of Science, Assiut University, Assiut, Egypt

\section{Email address:} \\ afsaad13@yahoo.com (A. Fawzy), iazaafarany@uqu.edu.sa (I. A. Zaafarany), kskhairou@uqu.edu.sa (K. S. Khairou), \\ lsmazroai@uqu.edu.sa (L. S. Almazroai), bajahdali@uqu.edu.sa (B. A. Al-Jahdali), tmbawazeer@uqu.edu.sa (T. M. Bawazeer)
}

\section{To cite this article:}

Ahmed Fawzy, Ishaq A. Zaafarany, Khalid S. Khairou, Layla S. Almazroai, Badriah A. Al-Jahdali, Tahani M. Bawazeer. Ruthenium(III)Catalyzed Oxidation of Vanillin by Anticancer Hexachloroplatinate(IV) Complex in Perchloric Acid Solutions: A Kinetic Study. American Journal of Physical Chemistry. Vol. 5, No. 3, 2016, pp. 56-64. doi: 10.11648/j.ajpc.20160503.12

Received: April 3, 2016; Accepted: April 9, 2016; Published: May 3, 2016

\begin{abstract}
The kinetics of oxidation of vanillin (VAN) by hexachloroplatinate(IV) has been investigated in perchloric acid solutions in the presence of ruthenium(III) catalyst at a constant ionic strength of $1.0 \mathrm{~mol} \mathrm{dm}^{-3}$ and at $25^{\circ} \mathrm{C}$. The progress of the reaction was followed spectrophotometrically. The reaction was not proceeding in the absence of the catalyst. The reaction exhibited first order kinetics with respect to both [HCP] and [Ru(III)] and less than unit order with respect to both [VAN] and $\left[\mathrm{H}^{+}\right]$. Increasing ionic strength and dielectric constant were found to increase the oxidation rate. The reaction mechanism adequately describing the kinetic results has been proposed. Both spectral and kinetic evidences revealed formation of an intermediate complex between vanillin substrate and ruthenium(III) catalyst prior to the rate-determining step. The complex reacts with the oxidant ( $\mathrm{HCP}$ ) by an inner-sphere mechanism leading to decomposition of the complex in the rate-determining step to give rise to the final oxidation products which were identified by both spectral and chemical analyses as vanillic acid and tetrachloroplatinate(II). The rate law expression for the catalyzed reaction was deduced. The reaction constants involved in the different steps of the reaction mechanism have been evaluated. The activation parameters associated with the rate-limiting step of the reaction, along with the thermodynamic quantities of the equilibrium constant have been evaluated and discussed.
\end{abstract}

Keywords: Catalyzed-Oxidation, Vanillin, Hexachloroplatinate(IV), Ruthenium(III), Kinetics, Mechanism

\section{Introduction}

Vanillin is a phenolic aldehyde, which is an organic compound including aldehyde, hydroxyl and ether. It is the primary component of the extract of the vanilla bean. Vanillin is a very popular flavouring reagent inthe food industry and widely used in the synthesis ofdrugssuch as Aldomet, L-Dopa (I) and Trimethaprin 2A. It has been also used as a chemical intermediate in the production of pharmaceuticals and other fine chemicals. Furthermore, it is used in the preparation of perfume and as acatalyst to various polymerization reactions. If the hydroxyl group in vanillin isprotected, it undergoes oxidation [1] to vanillic acid.
Oxidation of vanillin has previously been studied in alkaline media by few reagents, such as hexacyanoferrate(III) [2], diperiodatoargentate(III) [3], bismuth(V) [4], diperiodatonickelate(IV) [5] and by periodate catalyzed by ruthenium(III) [6], and in acid media by cerium(IV) [7].

Many metal ions in their complex form act as good oxidants in acidic, basic and neutral media. However, oxidation capacity depends on the redox potential of the metal ion and the latter depends on the $\mathrm{pH}$ of the medium. The chemistry of biologically active Pt(IV) complexes has become increasingly important over the last few decades due to their anticancer properties [8-11]. They have become attractive because they are usually substitution-inert, hence requiring reduction to $\mathrm{Pt}(\mathrm{II})$ species before they can act as 
potential anticancer drugs. The reduction of some $\mathrm{Pt}(\mathrm{IV})$ complexes with different reductants generally proceeds via a free radical one-electron transfer mechanism [12, 13]. An alternative path, whereby Pt(IV) undergoes a two-electron reduction process was also shown to occur [14]. The experimental conditions and choice of reductant determined whether a two-electron reduction process could occur.

Platinum(IV) complex in the form of hexachloroplatinate (IV) $(\mathrm{HCP}),\left[\mathrm{PtCl}_{6}\right]^{2-}$, has been used to oxidize a limited number of inorganic [12-16] and organic [17-29] compounds in different media. Knowledge of the reactivity of Pt(IV) compounds and their reduction by potential bioreductants, like vanillin, is important for understanding the mechanism of antitumor activity as well as for designing new compounds with fewer side effects. It has been reported [30] that there is a correlation between the rate of reduction and the anticancer activity in a series of homologous $\mathrm{Pt}(\mathrm{IV})$ complexes. However, no details of the reaction mechanism were provided.

Transition metal ions have been widely employed as homogenous catalysts for oxidation of organic and inorganic substrates [22-29, 31] by different reaction pathways such as formation of complexes with the reactants, oxidation of a substrate, or the formation of free radicals [32]. The present study deals with the oxidative behavior of hexachloroplatinate(IV) with vanillin in the presence of ruthenium(III) catalyst in order to explore the kinetic and mechanistic aspects of such redox reaction in a strong acid medium.

\section{Experimental}

\subsection{Materials}

Reagent grade chemicals and doubly distilled water were used throughout the work. A stock solution of vanillin was prepared afresh by dissolving vanillin sample (SD. Fine Chem.) in bidistilled water. Chloroplatinic acid solution (Johnson Matthey) was used without further purification. Required solution of the oxidant was freshly prepared before each experiment by proper dilution of its original solution which is standardized spectrophotometrically [33]. The solution was stored in a bottle away from light and restandardized periodically. Sodium pechlorate and acetic acid were used to vary the ionic strength and dielectric constant of the reaction medium, respectively.

\subsection{Kinetic Measurements}

All kinetic investigations were conducted under pseudofirst-order conditions where vanillin was present in a large excess over that of HCP. The ionic strength, $I$, of the reaction mixture was adjusted to 1.0 moldm $^{-3}$ using sodium perchlorate as an inert electrolyte. The reaction temperature $\left(25^{\circ} \mathrm{C}\right)$ was controlled within $\pm 0.1^{\circ} \mathrm{C}$ unless stated otherwise. The reaction was initiated by rapid addition of known amounts of the pre-equilibrated HCP to the reaction mixture containing the required amounts of vanillin, perchloric acid, $\mathrm{Ru}(\mathrm{III})$ chloride, sodium perchlorate and water, thermostated at the same temperature. The solutions were then mixed and transferred to a cell with a path length of $1 \mathrm{~cm}$. The course of the reaction was followed spectrophotometrically by monitoring the decrease in the absorbance of HCP at $\lambda=262$ $\mathrm{nm}$, its absorption maximum, as a function of time using Shimadzu UV-VIS-NIR-3600 double-beam spectrophotometer with a cell compartment kept at constant temperature. The applicability of Beer's law was verified at $262 \mathrm{~nm}$ under the reaction conditions. The molar extinction coefficient, $\varepsilon$, was determined $\left(\varepsilon=(1.32 \pm 0.04) \times 10^{4} \mathrm{dm}^{3} \mathrm{~mol}^{-1} \mathrm{~cm}^{-1}\right)$ and was found to be in a good agreement with that reported previously [33]. In addition, there is no interference from other reagents at this wavelength. It was observed that the oxidation reaction did not proceed in the absence of $\mathrm{Ru}(\mathrm{III})$ catalyst.

The pseudo-first order rate constant values of the catalyzed reaction $\left(k_{\mathrm{C}}\right)$ were obtained from the linear portion of $\ln$ (absorbance) versus time plots, which were the average of at least two independent kinetics runs and were reproducible to within $\pm 4 \%$. Double logarithmic plots were used to determine the order with respect to each reactant. The concentration of the particular species being examined was varied while the concentrations of the other species were held fixed.

\section{Results}

\subsection{Time-Resolved Spectra}

Time-resolved spectra during the course of the reaction between vanillin and HCP in the presence of $\mathrm{Ru}(\mathrm{III})$ catalyst are shown in Figure 1. The scanned spectra indicate gradual disappearance of the HCP absorption band with time as a result of its reduction. A hyposchromic shift in the HCP band of about $5 \mathrm{~nm}$ from 262 to $257 \mathrm{~nm}$ as well as two isosbestic points located at 241 and $297 \mathrm{~nm}$ are apparent in the spectra.

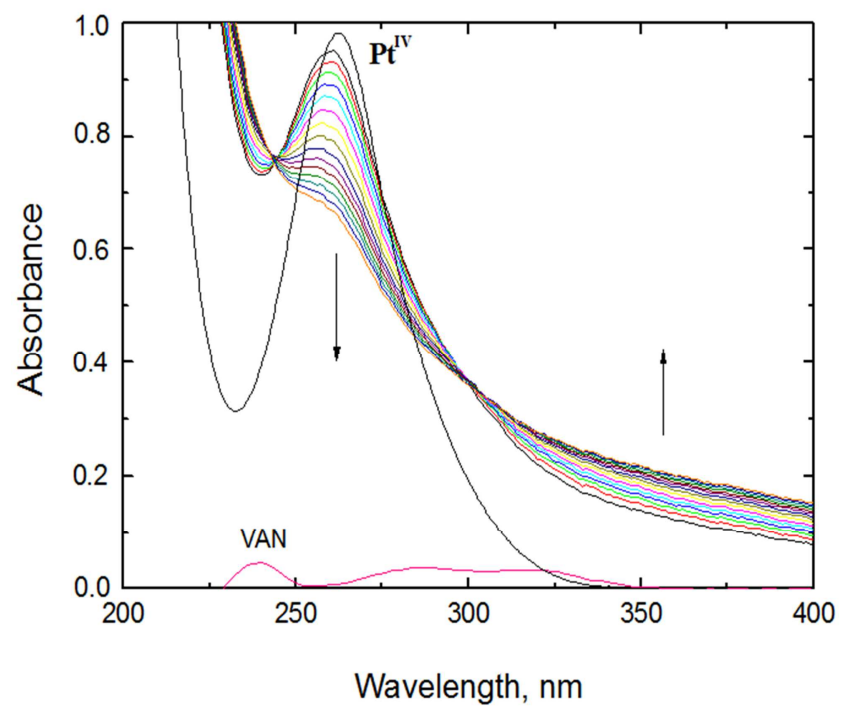

Figure 1. Time-resolved spectra during the Ru(III)-catalyzed oxidation of vanillin by HCP in perchloric acid solution. [VAN] $=8.0 \times 10^{-3},[H C P]=$ $8.0 \times 10^{-5},\left[\mathrm{H}^{+}\right]=0.5,[\mathrm{Ru}(\mathrm{III})]=6.0 \times 10^{-6}$ and $I=1.0 \mathrm{~mol} \mathrm{dm} \mathrm{m}^{-3}$ at $25^{\circ} \mathrm{C}$. Scanning time interval $=1.0 \mathrm{~min}$. 


\subsection{Stoichiometry and Product Identification}

Different reaction mixtures with different sets of reactants containing various amounts of HCP and vanillin at fixed acidity, ionic strength, and temperature were allowed to react for $24 \mathrm{~h}$ in an inert atmosphere. After completion of the reactions, the unreacted [HCP] was assayed spectrophotometrically. Results indicated that one mole of vanillin consumed one mole of HCP in the predominant reaction, as represented in the following equation:

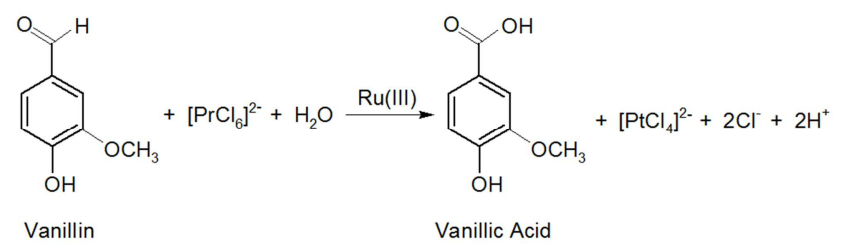

The above stoichiometric equation is consistent with the results of product analyses. The oxidation product of vanillin was identified as the corresponding carboxylic acid (vanillic acid) by both spectral and chemical analyses as reported earlier [34, 35]. Similar oxidation product of vanillin with different experimental conditions was reported earlier [2, 3].

On the other hand, formation of $\left[\mathrm{Pt}^{\mathrm{II}} \mathrm{Cl}_{4}\right]^{2-}$ was confirmed
[18] by the observed black precipitate of platinum(II) hydroxide on addition of alkali to the reaction mixture, according to the reaction, $\left[\mathrm{PtCl}_{4}\right]^{2-}+2 \mathrm{OH}^{-}=\mathrm{Pt}(\mathrm{OH})_{2}+4 \mathrm{Cl}^{-}$.

\subsection{Dependence of the Oxidation Rate on [HCP]}

The concentration of the oxidant, HCP, was varied in the range of $2.0 \times 10^{-5}$ to $14.0 \times 10^{-5} \mathrm{~mol} \mathrm{dm}^{-3}$ at constant [VAN], $[\mathrm{Ru}(\mathrm{III})],\left[\mathrm{H}^{+}\right]$, ionic strength and temperature. The nonvariation in the observed first order rate constants at various concentrations of HCP (Table 1) indicates that the order with respect to the oxidant is confirmed to be one.

\subsection{Dependence of the Oxidation Rate on [VAN]}

The observed first order rate constant $\left(k_{\mathrm{C}}\right)$ was determined at different initial concentrations of vanillin substrate keeping all other reactants concentration constant including $\mathrm{Ru}(\mathrm{III})$ catalyst. The results showed that the rate constant increased with increase in the vanillin concentration as listed in Table 1. A plot of $k_{\mathrm{C}}$ versus [VAN] was found to be linear with a positive intercept indicating less than unit order dependence with respect to vanillin (Figure 2).

Table 1. Effect of $[\mathrm{HCP}],[\mathrm{VAN}],\left[\mathrm{H}^{+}\right],[\mathrm{Ru}(\mathrm{III})]$ and ionic strength, I, on the observed first order rate constant (kc) in the Ru(III)-catalyzed oxidation of vanillin by $H C P$ in perchloric acid solutions at $25^{\circ} \mathrm{C}$. Experimental error $\pm 2 \%$.

\begin{tabular}{|c|c|c|c|c|c|}
\hline $10^{5}[\mathrm{HCP}]\left(\mathrm{mol} \mathrm{dm}^{-3}\right)$ & $10^{3}[\mathrm{VAN}]\left(\mathrm{mol} \mathrm{dm}^{-3}\right)$ & {$\left[\mathrm{H}^{+}\right]\left(\mathrm{mol} \mathrm{dm}^{-3}\right)$} & $10^{6}[\mathrm{Ru}(\mathrm{III})]\left(\mathrm{mol} \mathrm{dm}^{-3}\right)$ & $I\left(\mathrm{~mol} \mathrm{dm}^{-3}\right)$ & $10^{5} k_{\mathrm{C}}\left(\mathrm{s}^{-1}\right)$ \\
\hline 2.0 & 8.0 & 0.5 & 6.0 & 1.0 & 15.2 \\
\hline 4.0 & 8.0 & 0.5 & 6.0 & 1.0 & 14.9 \\
\hline 6.0 & 8.0 & 0.5 & 6.0 & 1.0 & 15.7 \\
\hline 8.0 & 8.0 & 0.5 & 6.0 & 1.0 & 15.6 \\
\hline 10.0 & 8.0 & 0.5 & 6.0 & 1.0 & 14.3 \\
\hline 12.0 & 8.0 & 0.5 & 6.0 & 1.0 & 16.1 \\
\hline 14.0 & 8.0 & 0.5 & 6.0 & 1.0 & 15.9 \\
\hline 8.0 & 4.0 & 0.5 & 6.0 & 1.0 & 9 \\
\hline 8.0 & 6.0 & 0.5 & 6.0 & 1.0 & 12 \\
\hline 8.0 & 8.0 & 0.5 & 6.0 & 1.0 & 15.6 \\
\hline 8.0 & 10.0 & 0.5 & 6.0 & 1.0 & 18.6 \\
\hline 8.0 & 12.0 & 0.5 & 6.0 & 1.0 & 21.55 \\
\hline 8.0 & 14.0 & 0.5 & 6.0 & 1.0 & 24 \\
\hline 8.0 & 8.0 & 0.2 & 6.0 & 1.0 & 8 \\
\hline 8.0 & 8.0 & 0.4 & 6.0 & 1.0 & 13 \\
\hline 8.0 & 8.0 & 0.5 & 6.0 & 1.0 & 15.6 \\
\hline 8.0 & 8.0 & 0.6 & 6.0 & 1.0 & 18 \\
\hline 8.0 & 8.0 & 0.7 & 6.0 & 1.0 & 20 \\
\hline 8.0 & 8.0 & 0.8 & 6.0 & 1.0 & 22 \\
\hline 8.0 & 8.0 & 0.5 & 2.0 & 1.0 & 4.6 \\
\hline 8.0 & 8.0 & 0.5 & 4.0 & 1.0 & 11 \\
\hline 8.0 & 8.0 & 0.5 & 6.0 & 1.0 & 15.6 \\
\hline 8.0 & 8.0 & 0.5 & 8.0 & 1.0 & 21 \\
\hline 8.0 & 8.0 & 0.5 & 10.0 & 1.0 & 27 \\
\hline 8.0 & 8.0 & 0.5 & 12.0 & 1.0 & 32 \\
\hline 8.0 & 8.0 & 0.5 & 14.0 & 1.0 & 36 \\
\hline 8.0 & 8.0 & 0.5 & 6.0 & 1.0 & 15.6 \\
\hline 8.0 & 8.0 & 0.5 & 6.0 & 1.2 & 17.2 \\
\hline 8.0 & 8.0 & 0.5 & 6.0 & 1.4 & 18.9 \\
\hline 8.0 & 8.0 & 0.5 & 6.0 & 2.0 & 23.4 \\
\hline 8.0 & 8.0 & 0.5 & 6.0 & 2.2 & 24.7 \\
\hline
\end{tabular}




\subsection{Dependence of the Oxidation Rate on $\left[\mathrm{H}^{+}\right]$}

The reaction rate was measured at constant [VAN], [HCP], $[\mathrm{Ru}(\mathrm{III})]$, ionic strength and temperature but with various $\left[\mathrm{H}^{+}\right]\left(0.2-0.8 \mathrm{~mol} \mathrm{dm}^{-3}\right)$. The rate of reaction was found to increase as $\left[\mathrm{H}^{+}\right]$increased with less than unit order as the slope of the plot of $\log k_{\mathrm{C}}$ versus $\log \left[\mathrm{H}^{+}\right]$(slope $=$order $=$ 0.72 ) as illustrated in Figure 3.

\subsection{Dependence of the Oxidation Rate on [Ru(III)]}

The reaction rate was measured with various $[\mathrm{Ru}(\mathrm{III})]$, $(2.0-14.0) \times 10^{-6} \mathrm{~mol} \mathrm{dm}^{-3}$ at constant other variables. The reaction rate increased with the increase in $[\mathrm{Ru}(\mathrm{III})]$ (Table 1). The order with respect to $[R u(I I I)]$ was found to be unity as the slope of $\log k_{\mathrm{C}}$ versus $\log [\mathrm{Ru}(\mathrm{III})]$ plot (Figure 4).

\subsection{Dependence of the Oxidation Rate on Ionic Strength and Dielectric Constant}

The effect of ionic strength on the oxidation rate was studied by the addition of sodium perchlorate to the reaction medium at constant concentration of vanillin, $\mathrm{HCP}, \mathrm{Ru}(\mathrm{III})$, and at constant $\mathrm{pH}$ and temperature. The results are presented in Table 1. These results showed that the rate constant increased with increase in the ionic strength of the medium, and the Debye-Hückel plot was found to be linear with a positive slope as shown in Figure 5.

The reaction was studied at different solvent compositions $(\mathrm{v} / \mathrm{v})$ of acetic acid and water. The dielectric constant of the medium (D) at different compositions was calculated using the dielectric constants of water and acetic acid as 78.5 and 6.15 , respectively, at $25^{\circ} \mathrm{C}$. The rate constant was found to decrease with the decrease in dielectric constant of the solvent mixture, i.e., increase in acetic acid content. The plot of $\log k_{\mathrm{C}}$ versus $1 / D$ was found to be linear with anegative slope as shown in Figure 6.

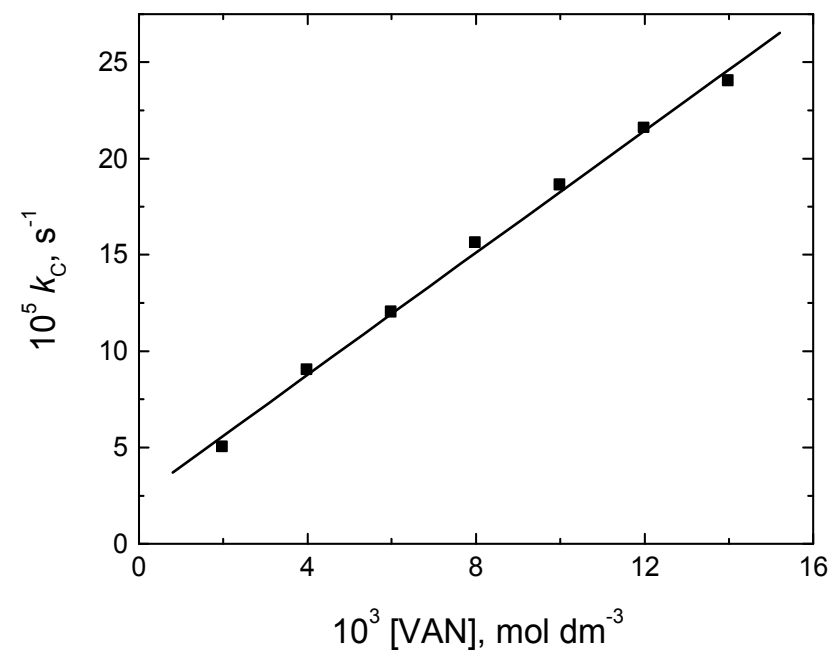

Figure 2. Plot of the observed first order rate constant $\left(k_{C}\right)$ versus [VAN] in the Ru(III)-catalyzed oxidation of vanillin by HCP in perchloric acid solution. $[\mathrm{HCP}]=8.0 \times 10^{-5},\left[\mathrm{H}^{+}\right]=0.5,[\mathrm{Ru}(\mathrm{III})]=6.0 \times 10^{-6}$ and $I=1.0 \mathrm{~mol}$ $d m^{-3}$ at $25^{\circ} \mathrm{C}$.

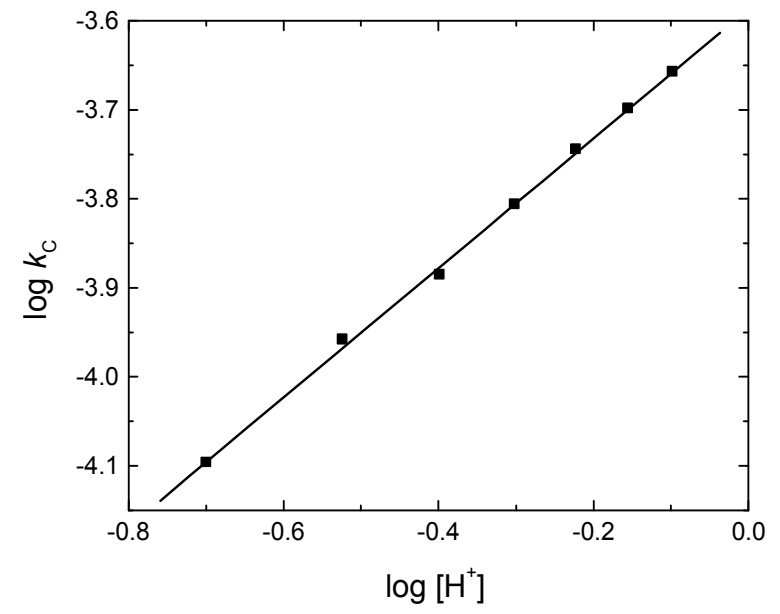

Figure 3. Plot of $\log k_{C}$ versus $\log \left[H^{+}\right]$in the Ru(III)-catalyzed oxidation of vanillin by $H C P$ in perchloric acid solutions. $[V A N]=8.0 \times 10^{-3},[H C P]=$ $8.0 \times 10^{-5},[R u(I I I)]=6.0 \times 10^{-6}$ and $I=1.0 \mathrm{~mol} \mathrm{dm}^{-3}$ at $25^{\circ} \mathrm{C}$.

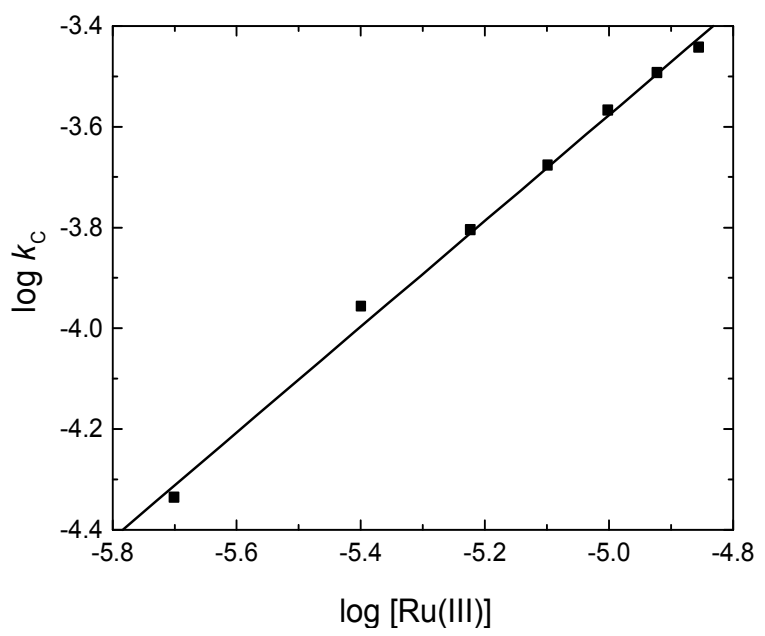

Figure 4. Plot of $\log k_{C}$ versus $\log [R u(I I I)]$ in the Ru(III)-catalyzed oxidation of vanillin by $H C P$ in perchloric acid solution. $[V A N]=8.0 \times 10^{-3}$, $[H C P]=8.0 \times 10^{-5},\left[H^{+}\right]=0.5$ and $I=1.0 \mathrm{~mol} \mathrm{dm} m^{-3}$ at $25^{\circ} \mathrm{C}$.

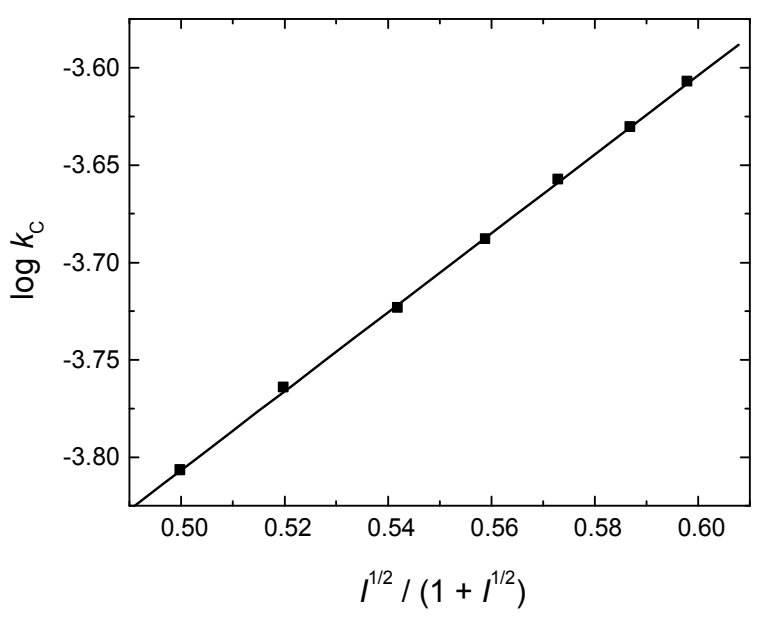

Figure 5. Debye-Hückel plots in the Ru(III)-catalyzed oxidation of vanillin by $\mathrm{HCP}$ in perchloric acid solution. $[\mathrm{VAN}]=8.0 \times 10^{-3},[\mathrm{HCP}]=8.0 \times 10^{-5}$, $\left[H^{+}\right]=0.5$ and $[R u(I I I)]=6.0 \times 10^{-6} \mathrm{~mol} \mathrm{dm}^{-3}$ at $25^{\circ} \mathrm{C}$. 


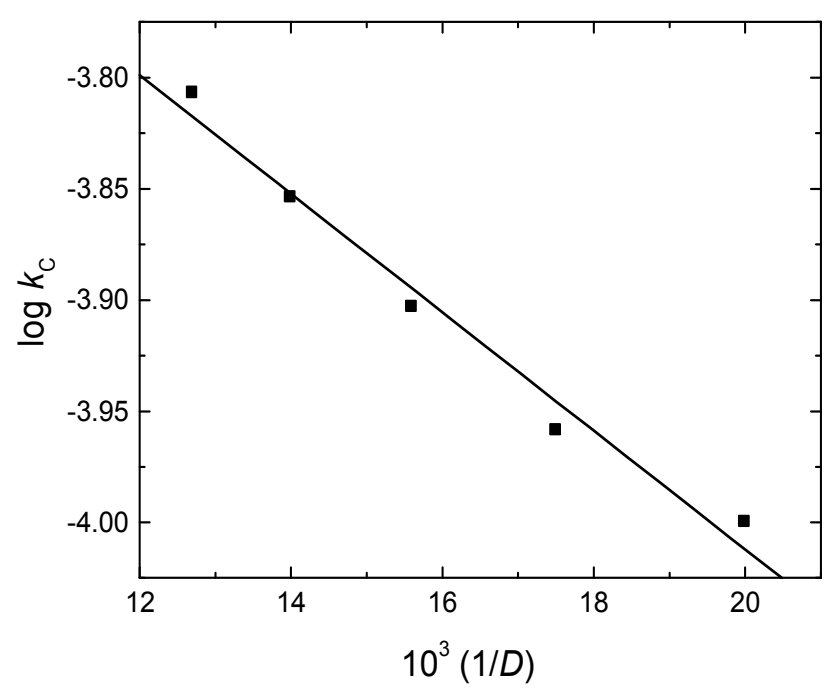

Figure 6. Effect of solvent composition on the observed first order rate constant. Plot of log $k_{C}$ versus $1 / D$ for the Ru(III)-catalyzed oxidation of vanillin by $H C P$ in perchloric acid solution. $[V A N]=8.0 \times 10^{-3},[H C P]=$ $8.0 \times 10^{-5},\left[H^{+}\right]=0.5,[R u(I I I)]=6.0 \times 10^{-6}$ and $I=1.0 \mathrm{~mol} \mathrm{dm}^{-3}$ at $25^{\circ} \mathrm{C}$.

\subsection{Dependence of the Oxidation Rate on Temperature}

The rate of $\mathrm{Ru}(\mathrm{III})$-catalyzed oxidation of vanillin by HCP in perchloric acid solutions was measured at five different temperatures namely, 293, 298, 303, 308 and $313 \mathrm{~K}$ under varying vanillin substrate and acid concentrations. The reaction rate was found to increase with raising temperature. The activation parameters of the rate constant of the slow step $\left(k_{1}\right)$ along with thermodynamic parameters of the equilibrium constants involved in the reaction mechanisms were evaluated using Arrhenius and Eyring equations and were listed in Tables 3 and 4, respectively.

\subsection{Test for Free Radical Intermediates}

To study the possible intervention of free radicals during the oxidation reaction, the reaction mixture to which a known quantity of acrylonitrile scavenger was initially added was kept for $8 \mathrm{~h}$ in an inert atmosphere. On diluting the mixtures with methanol, no white precipitate was formed, thus confirming the absence of free radical intervention in the present reaction.

\section{Discussion}

It was reported $[36,37]$ that the reactive species of $\mathrm{Ru}(\mathrm{III})$ chloride in acid media is $\left[\mathrm{RuCl}_{5}\left(\mathrm{H}_{2} \mathrm{O}\right)\right]^{2-}$ (assigned as $\left.\mathrm{Ru}(\mathrm{III})^{*}\right)$. Also, it was reported $[4,6]$ that vanillin forms intermediate complexes with transition metal ions. This may be due to the availability of the electron pairs on both oxygen atoms of the carbonyl and hydroxyl groups which may act as nucleophiles, depending on $\mathrm{pH}$ of the medium. The protolytic group with the highest basicity interacts with metal ion. Thus, at low $\mathrm{pH}$ where the hydroxyl group is protonated, the carbonyl group should be able to attack metal ion.

Platinum(IV) species in acid medium is present as $\left[\mathrm{PtCl}_{6}\right]^{2-}$, which is assumed to be the principal reactive oxidant [38]. The reduction of $\left[\mathrm{PtCl}_{6}\right]^{2-}$ generally proceeds as follows:

$$
\left[\mathrm{PtCl}_{6}\right]^{2-}+2 \mathrm{e}^{-}=\left[\mathrm{PtCl}_{4}\right]^{2-}+2 \mathrm{Cl}^{-}
$$

In this reduction process, octahedral $\mathrm{Pt}(\mathrm{IV})$ is reduced to square planar $\mathrm{Pt}(\mathrm{II})$ with release of two $\mathrm{Cl}^{-}$ions. Therefore, this reaction is better classified as a reductive-elimination reaction [9, 11]. Because platinum(IV) complexes are generally substitution-inert [39], initial complex formation between platinum(IV) and reductant prior to electron transfer can be excluded in reductive-elimination reactions.

Two alternative reaction mechanisms for the oxidation by HCP may be considered. The first mechanism involves a simultaneous two-electron transfer in a single step. The second mechanism involves two successive one-electron transfer steps. If the transition states of the reductant and/or oxidant are unstable, a simultaneous two-electron transfer mechanism may be suggested, such as that in the oxidation of uranium(IV) by $\left[\mathrm{PtCl}_{6}\right]^{2-}[40]$. In the present study, addition of acrylonitrile monomer to the reaction mixture failed to give polymerized products. It may be that a free radical such as the $\mathrm{Pt}$ (III) species is too short-lived to interact with acrylonitrile to give the polymerized product under our experimental conditions. Consequently, the two-electron transfer mechanism seems plausible.

The present reaction between HCP and vanillin in the presence of micro amounts of $\mathrm{Ru}$ (III) catalyst had a stoichiometry of 1:1 with a first order dependence on both $[\mathrm{HCP}]$ and $[\mathrm{Ru}(\mathrm{III})]$, and less than unit orders with respect to both $[\mathrm{VAN}]$ and $\left[\mathrm{H}^{+}\right]$. The observed increasein the reaction rate upon increasing acid concentration suggests protonation of vanillin substrate (VAN)prior to the rate-determining step to form protonated vanillin $\left(\mathrm{VANH}^{+}\right)$as a more reactive species, which plays the main role in the reaction kinetics as illustrated by step (I) in the mechanistic Scheme 1.The less than unit order with respect to [VAN] suggests formation of an intermediate complex between vanillin substrate and $\mathrm{Ru}$ (III) catalyst prior to the reaction with the oxidant, step (II). Complex formation was proved kinetically by the nonzero intercepts of the plots of [Ru(III)] / $k_{\mathrm{C}}$ versus 1/[VAN] (Figure 7) [41]. Spectroscopic evidence to support complex formation between vanillin and $\mathrm{Ru}(\mathrm{III})$ which obtained from the UV-Vis spectra was the observed hyposchromic shift in the wavelength with appearance of two isosbestic points as shown in Figure 1. Also, the oxidation rate increased upon increasing both ionic strength and dielectric constant of the medium, suggesting that the reaction occurred between two similarly charged ions [42-45].

Based on the forthcoming arguments, the suggested mechanism shown in Scheme 1 involves combination of the protonated vanillin with the reactive species of the catalyst, $\mathrm{Ru}(\mathrm{III})^{*}$, to form an intermediate complex, [VANH ${ }^{+}-$ $\left.\mathrm{Ru}(\mathrm{III})^{*}\right]^{-}(\mathrm{C})$. The complex reacts in a slow step with HCPleading to formation of vanillin cation with regeneration of the catalyst $\mathrm{Ru}(\mathrm{III})^{*}$, step (III), which rapidly hydrolyze to give rise to the oxidation product of vanillin (vanillic acid) as illustrated by step (IV). 


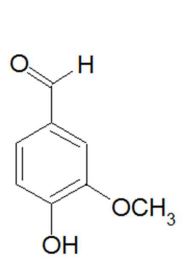

(VAN)

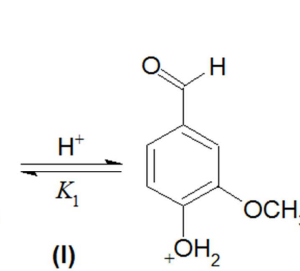

$\left(\mathrm{VANH}^{+}\right)$

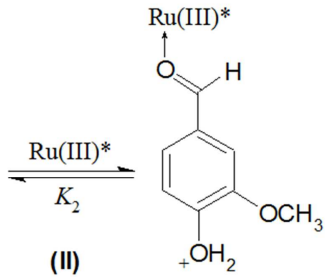

(C)

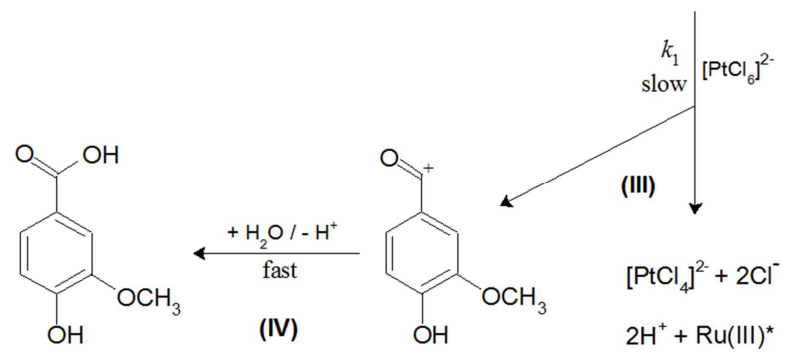

Scheme 1. Mechanism of Ru(III)-catalyzed oxidation of vanillin by HCP in perchloric acid solution.

The suggested mechanism leads to the following rate law expression:

$$
\text { Rate }=\frac{-d[\mathrm{HCP}]}{d t}=\frac{+d[\mathrm{C}]}{d t}=k_{1}[\mathrm{C}][\mathrm{HCP}]
$$

The relationship between the rate of complex formation and the substrate, hydrogen ion, catalyst and oxidant concentrations can be deduced to give the following rate-law expression:

$$
\text { Rate }=\frac{k_{1} K_{1} K_{2}[\mathrm{VAN}]\left[\mathrm{H}^{+}\right][\mathrm{Ru}(\mathrm{III})[\mathrm{HCP}]}{\left(1+K_{1}\left[\mathrm{H}^{+}\right]+K_{1} K_{2}\left[\mathrm{H}^{+}\right]\left[\mathrm{Ru}(\mathrm{III}) \mathrm{D}\left(1+K_{1} K_{2}[\mathrm{VAN}]\left[\mathrm{H}^{+}\right]\right)\right.\right.}
$$

In view of low concentration of $[\mathrm{Ru}(\mathrm{III})]$ used, the term $K_{1} K_{2}\left[\mathrm{H}^{+}\right][\mathrm{Ru}(\mathrm{III})]$ in the denominator can be neglected. Therefore, Eq. (2) becomes,

$$
\text { Rate }=\frac{k_{1} K_{1} K_{2}[\mathrm{VAN}]\left[\mathrm{H}^{+}\right][\mathrm{Ru}(\mathrm{III})][\mathrm{HCP}]}{1+K_{1}\left[\mathrm{H}^{+}\right]+K_{1} K_{2}[\mathrm{VAN}]\left[\mathrm{H}^{+}\right]}
$$

Under pseudo-first order condition,

$$
\text { Rate }=\frac{-d[\mathrm{HCP}]}{d t}=k_{\mathrm{C}}[\mathrm{HCP}]
$$

Comparing Eqs. (3) and (4) and rearrangement, we obtain,

$$
\begin{aligned}
& \frac{[\mathrm{Ru}(\mathrm{III})]}{k_{\mathrm{C}}}=\left(\frac{1}{k_{1} K_{1} K_{2}\left[\mathrm{H}^{+}\right]}+\frac{1}{k_{1} K_{2}}\right) \frac{1}{[\mathrm{VAN}]}+\frac{1}{k_{1}} \\
& \frac{[\mathrm{Ru}(\mathrm{III})]}{k_{\mathrm{C}}}=\left(\frac{1}{k_{1} K_{1} K_{2}[\mathrm{VAN}]}\right) \frac{1}{\left[\mathrm{H}^{+}\right]}+\frac{1}{k_{1} K_{2}[\mathrm{VAN}]}+\frac{1}{k_{1}}
\end{aligned}
$$

According to Eqs. (5) and (6), the plots of $[\mathrm{Ru}(\mathrm{III})] / k_{\mathrm{C}}$ versus $1 /[\mathrm{VAN}]$, at constant $\left[\mathrm{H}^{+}\right]$, and $[\mathrm{Ru}(\mathrm{III})] / k_{\mathrm{C}}$ against $1 /\left[\mathrm{H}^{+}\right]$, at constant $[\mathrm{VAN}]$, should be linear with positive intercepts on $[\mathrm{Ru}(\mathrm{III})] / k_{\mathrm{C}}$ axes. The experimental results satisfied this requirement as shown in Figures 7 and 8. From the slopes and intercepts of these Figures, the values of the rate constant of the slow step $\left(k_{1}\right)$ and the equilibrium constants involved in the first two steps of the mechanistic Scheme $1\left(K_{1} \& K_{2}\right)$ were evaluated at different temperatures and were listed in Table 2. Also, the activation parameters of $k_{1}$ along with thermodynamic parameters of $K_{1}$ and $K_{2}$ were calculated and were listed in Tables 3 and 4, respectively.

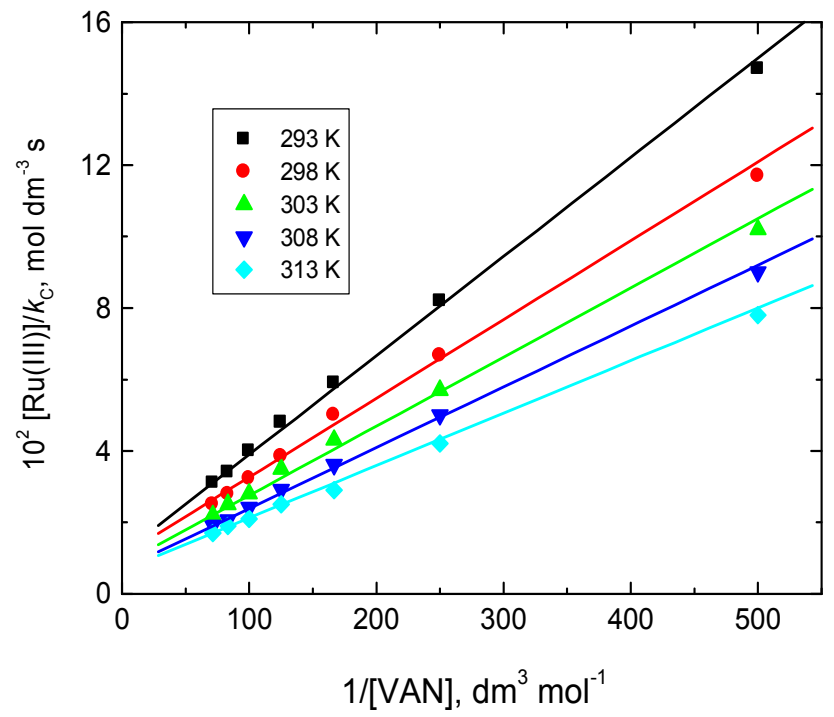

Figure 7. Verification of equation (5) in the Ru(III)-catalyzed oxidation of vanillin by $H C P$ in perchloric acid solutions at different temperatures. $[\mathrm{HCP}]=8.0 \times 10^{-5},\left[\mathrm{H}^{+}\right]=0.5$ and $I=1.0 \mathrm{~mol} \mathrm{dm} \mathrm{m}^{-3}$.

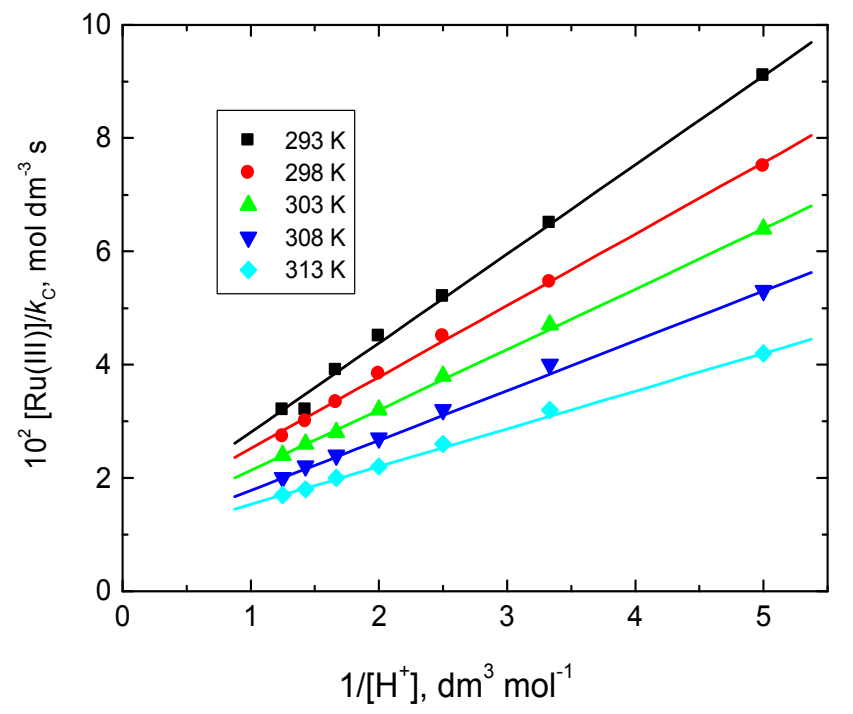

Figure 8. Verification of equation (6) in the Ru(III)-catalyzed oxidation of vanillin by HCP in perchloric acid solutions at different temperatures. $[V A N]=8.0 \times 10^{-3},[H C P]=8.0 \times 10^{-5}$ and $I=1.0 \mathrm{~mol} \mathrm{dm}^{-3}$. 
Table 2. Values of the rate constants of the slow step $\left(k_{1}\right)$ and the equilibrium constants $\left(K_{I}\right.$ and $\left.K_{2}\right)$ in the Ru(III)-catalyzed oxidation of vanillin by HCP in perchloric acid solutions at different temperatures.

\begin{tabular}{llllll}
\hline \multirow{2}{*}{ Constant } & Temperature (K) & & & \\
\cline { 2 - 6 } & $\mathbf{2 9 3}$ & $\mathbf{2 9 8}$ & $\mathbf{3 0 3}$ & $\mathbf{3 0 8}$ & $\mathbf{3 1 3}$ \\
\hline$k_{1}\left(\mathrm{dm}^{3} \mathrm{~mol}^{-1} \mathrm{~s}^{-1}\right)$ & 85.49 & 102.31 & 121.48 & 142.85 & 166.20 \\
$10^{2} K_{1}\left(\mathrm{dm}^{3} \mathrm{~mol}^{-1}\right)$ & 11.31 & 13.70 & 17.88 & 25.21 & 38.07 \\
$10^{-2} K_{2}\left(\mathrm{dm}^{3} \mathrm{~mol}^{-1}\right)$ & 8.29 & 6.93 & 5.46 & 4.03 & 3.05 \\
\hline
\end{tabular}

Table 3. Activation parameters associated with the slow step $\left(k_{1}\right)$.

\begin{tabular}{|c|c|c|c|c|}
\hline$\Delta \mathbf{S}^{ \pm} \mathbf{J ~ m o l}^{-1} \mathbf{K}^{-1}$ & $\Delta \mathrm{H}^{\ddagger} \mathrm{kJ} \mathrm{mol}^{-1}$ & $\Delta \mathbf{G}_{298}^{\neq} \mathrm{kJ} \mathrm{mol}^{-1}$ & $\mathrm{E}_{\mathrm{a}}{ }^{\neq} \mathrm{kJ} \mathrm{mol}^{-1}$ & $A \mathrm{~mol}^{-1} \mathrm{~s}^{-1}$ \\
\hline-83.12 & 24.04 & 48.81 & 25.35 & $7.08 \times 10^{13}$ \\
\hline
\end{tabular}

Table 4. Thermodynamic parameters associated with the equilibrium constants $\left(K_{1}\right.$ and $\left.K_{2}\right)$.

\begin{tabular}{|c|c|c|c|}
\hline Equilibrium Constant & $\Delta H^{o} \mathrm{~kJ} \mathrm{~mol}^{-1}$ & $\Delta G^{o}{ }_{298} \mathrm{~kJ} \mathrm{~mol}^{-1}$ & $\Delta S^{o} \mathrm{~J} \mathrm{~mol}^{-1} \mathrm{~K}^{-1}$ \\
\hline$K_{1}$ & 46.18 & 4.95 & 138.34 \\
\hline$K_{2}$ & -38.69 & -16.02 & -75.46 \\
\hline
\end{tabular}

Experimental error $\pm 3 \%$

The negative value of $\Delta S^{\ddagger}$ indicates that there is a decrease in the randomness during the oxidation process. This leads to the formation of compacted intermediate complex and such activated complex is more ordered than the reactants due to loss of degree of freedom [46, 47]. Again, the negative values of both $\Delta H^{\neq}$and $\Delta G^{\neq}$indicate the exothermic formation of the intermediate and its spontaneity, respectively.

\section{Conclusions}

The reaction between vanillinand hexachloroplatinate(IV) in perchloric acid solution did not proceed in the absence of $\mathrm{Ru}(\mathrm{III})$ catalyst. Plausible mechanistic scheme of the catalyzed oxidation reaction has been proposed. The final oxidation product of vanillinwas identified as vanillic acid.

\section{Appendix A.}

Derivation of the Rate Law Expression:

According to the proposed mechanistic Scheme 1,

$$
\begin{aligned}
& \text { Rate }=\frac{-d[\mathrm{HCP}]}{d t}=\frac{+d[\mathrm{C}]}{d t}=k_{1}[\mathrm{C}][\mathrm{HCP}] \\
& K_{1}=\frac{\left[\mathrm{VANH}^{+}\right]}{[\mathrm{VAN}]\left[\mathrm{H}^{+}\right]},\left[\mathrm{VANH}^{+}\right]=K_{1}[\mathrm{VAN}]\left[\mathrm{H}^{+}\right]
\end{aligned}
$$

$$
K_{2}=\frac{[\mathrm{C}]}{\left[\mathrm{VANH}^{+}\right][\mathrm{Ru}(\mathrm{III})]},
$$

$$
[\mathrm{C}]=K_{2}\left[\mathrm{VANH}^{+}\right][\mathrm{Ru}(\mathrm{III})]=K_{1} K_{2}[\mathrm{VAN}]\left[\mathrm{H}^{+}\right][\mathrm{Ru}(\mathrm{III})]
$$

Substituting Eq. (A3) into Eq. (A1) leads to,

$$
\text { Rate }=k_{1} K_{1} K_{2}[\mathrm{VAN}]\left[\mathrm{H}^{+}\right][\mathrm{Ru}(\mathrm{III})][\mathrm{HCP}]
$$

The total concentration of vanillin is given by,

$$
[\mathrm{VAN}]_{\mathrm{T}}=[\mathrm{VAN}]_{\mathrm{F}}+\left[\mathrm{VANH}^{+}\right]+[\mathrm{C}]
$$

where ' $\mathrm{T}$ ' and ' $\mathrm{F}$ ' stand for total and free concentrations.
Substituting Eqs. (A2) and (A3) into Eq. (A5) and rearrangement gives,

$[\mathrm{VAN}]_{\mathrm{T}}=[\mathrm{VAN}]_{\mathrm{F}}+K_{1}[\mathrm{VAN}]\left[\mathrm{H}^{+}\right]+K_{1} K_{2}[\mathrm{VAN}]\left[\mathrm{H}^{+}\right][\mathrm{Ru}(\mathrm{III})](\mathrm{A} 6)$

$[\mathrm{VAN}]_{\mathrm{T}}=[\mathrm{VAN}]_{\mathrm{F}}\left(1+K_{1}\left[\mathrm{H}^{+}\right]+K_{1} K_{2}\left[\mathrm{H}^{+}\right][\mathrm{Ru}(\mathrm{III})]\right)$

Therefore,

$$
[\mathrm{VAN}]=\frac{\left[\mathrm{VAN}_{\mathrm{T}}\right.}{1+K_{1}\left[\mathrm{H}^{+}\right]+K_{1} K_{2}\left[\mathrm{H}^{+}\right][\mathrm{Ru}(\mathrm{III})]}
$$

In view of low $[\mathrm{Ru}(\mathrm{III})]$, the third denominator term $K_{1} K_{2}\left[\mathrm{H}^{+}\right][\mathrm{Ru}(\mathrm{III})]$ in the above equation can be neglected. Therefore, Eq. (A8) can be simplified to the following,

$$
\begin{aligned}
& {[\mathrm{VAN}]=\frac{[\mathrm{VAN}]_{\mathrm{T}}}{1+K_{1}\left[\mathrm{H}^{+}\right]}} \\
& {[\mathrm{Ru}(\mathrm{III})]_{\mathrm{T}}=[\mathrm{Ru}(\mathrm{III})]_{\mathrm{F}}+[\mathrm{C}]} \\
& {[\mathrm{Ru}(\mathrm{III})]_{\mathrm{T}}=[\mathrm{Ru}(\mathrm{III})]_{\mathrm{F}}\left(1+K_{1} K_{2}[\mathrm{VAN}]\left[^{+}\right]\right)} \\
& {[\mathrm{Ru}(\mathrm{III})]_{\mathrm{F}}=\frac{[\mathrm{Ru}(\mathrm{III})]_{\mathrm{T}}}{1+K_{1} K_{2}[\mathrm{VAN}]\left[\mathrm{H}^{+}\right]}}
\end{aligned}
$$

Regarding to the high concentration of $\mathrm{H}^{+}$,

$$
\left[\mathrm{H}^{+}\right]_{\mathrm{F}}=\left[\mathrm{H}^{+}\right]_{\mathrm{T}}
$$

Substituting Eqs. (A9), (A12) and (A13) into Eq. (A4) (and omitting ' $\mathrm{T}$ ' and ' $\mathrm{F}$ ' subscripts) leads to,

$$
\begin{aligned}
& \text { Rate }=\frac{k_{1} K_{1} K_{2}[\mathrm{VAN}]\left[\mathrm{H}^{+}\right][\mathrm{Ru}(\mathrm{III})][\mathrm{HCP}]}{\left(1+K_{1}\left[\mathrm{H}^{+}\right]\right)\left(1+K_{1} K_{2}[\mathrm{VAN}]\left[\mathrm{H}^{+}\right]\right)} \\
& \text {Rate }=\frac{k_{1} K_{1} K_{2}[\mathrm{VAN}]\left[\mathrm{H}^{+}\right][\mathrm{Ru}(\mathrm{III})][\mathrm{HCP}]}{1+K_{1}\left[\mathrm{H}^{+}\right]+K_{1} K_{2}[\mathrm{VAN}]\left[\mathrm{H}^{+}\right]+K_{1}^{2} K_{2}[\mathrm{VAN}]\left[\mathrm{H}^{+}\right]^{2}}
\end{aligned}
$$

The term $K_{1}^{2} K_{2}[\mathrm{VAN}]\left[\mathrm{H}^{+}\right]^{2}$ in the denominator of Eq. (A15) is negligibly small compared to unity in view of the low concentration of VAN used. Therefore Eq. (A15) can be written as, 


$$
\text { Rate }=\frac{k_{1} K_{1} K_{2}[\mathrm{VAN}]\left[\mathrm{H}^{+}\right][\mathrm{Ru}(\mathrm{III})][\mathrm{HCP}]}{1+K_{1}\left[\mathrm{H}^{+}\right]+K_{1} K_{2}[\mathrm{VAN}]\left[\mathrm{H}^{+}\right]}
$$

Under pseudo-first order condition, the rate-law can be expressed by Eq. (A17),

$$
\text { Rate }=\frac{-d[\mathrm{HCP}]}{d t}=k_{C}[\mathrm{HCP}]
$$

Therefore, comparing Eqs. (A16) and (A17), the following relationship is obtained,

$$
k_{C}=\frac{k_{1} K_{1} K_{2}[\mathrm{VAN}]\left[\mathrm{H}^{+}\right][\mathrm{Ru}(\mathrm{III})]}{1+K_{1}\left[\mathrm{H}^{+}\right]+K_{1} K_{2}[\mathrm{VAN}]\left[\mathrm{H}^{+}\right]}
$$

Equation (A16) can be rearranged to the following forms, which is suitable for verification,

$$
\begin{aligned}
& \frac{[\mathrm{Ru}(\mathrm{III})]}{k_{\mathrm{C}}}=\left(\frac{1}{k_{1} K_{1} K_{2}\left[\mathrm{H}^{+}\right]}+\frac{1}{k_{1} K_{2}}\right) \frac{1}{[\mathrm{VAN}]}+\frac{1}{k_{1}} \\
& \frac{[\mathrm{Ru}(\mathrm{III})]}{k_{\mathrm{C}}}=\left(\frac{1}{k_{1} K_{1} K_{2}[\mathrm{VAN}]}\right) \frac{1}{\left[\mathrm{H}^{+}\right]}+\frac{1}{k_{1} K_{2}[\mathrm{VAN}]}+\frac{1}{k_{1}}
\end{aligned}
$$

\section{References}

[1] Liu Y, Liu H, Li Y (2008) Comparative study of the electrocatalytic oxidation and mechanism of nitrophenols at $\mathrm{Bi}$ doped lead dioxide. Appl. Catal. B: Env. 84: 297-302.

[2] Timy PJ, Nandibewoor ST, Tuwar SM (2006) Kinetics and mechanism of the oxidation of vanillin by hexacyanoferrate (III) in aqueous alkaline medium. J. Solution Chem. 35: 5162.

[3] Deepak SM, Chimatadar SA, Nandibewoor ST (2007) Oxidation of vanillin by a new oxidant diperiodatoargentate (III) in aqueous alkaline medium. Ind. Eng. Chem. Res. 46: $1459-1464$

[4] Mishra P (2009) Kinetics and mechanisms of oxidation of 4hydroxy-3-methoxy benzaldehyde (vanillin) by $\mathrm{Bi}(\mathrm{V})$ in aqueous alkaline medium. Int. J. Pharm. Tech. Res. 1: 1234-1240.

[5] Kathari C, Pol P, Nandibewoor ST (2002) The kinetics and mechanism of oxidation of vanillin by diperiodatonickelate (IV) in aqueous alkaline medium. Turk. J. Chem. 26: 229236.

[6] Patil DG, Magdum PA, Nandibewoor ST (2015) Mechanistic investigations of uncatalyzed and ruthenium(III) catalyzed oxidation of vanillin by periodate in aqueous alkaline medium, J. Solution Chem.44: 1205-1223.

[7] Satapathy PK, Baral DK, Aswar, AS, Mohanty P (2013) Kinetics and mechanism of oxidation of vanillin by cerium(IV) in aqueous perchlorate medium. Indian J. Chem. Tech. 20: 271-275.

[8] Keage MC, Kelland MJ, Neidles LR, Warning MJ, ed. (1993) Molecular Aspects of Anticancer Drug DNA Interactions, vol. 1, CRC Press, New York, NY, USA.

[9] Lemma K, Sargeson A, Elding LI (2000) Kinetics and mechanism for reduction of oral anticancer platinum(IV) dicarboxylate compounds by L-ascorbate ions. J. Chem. Soc. Dalton Trans. 7: 1167-1172.

[10] Weiss RP, Christian MC (1993) New cisplatin analogues in development. A review. Drugs 46: 360-377.

[11] Lemma K, Shi T, Elding LI (2000) Kinetics and mechanism for reduction of the anticancer prodrug trans, trans, trans$\left[\mathrm{PtCl}_{2}(\mathrm{OH})_{2}\left(\mathrm{c}_{-} \mathrm{C}_{6} \mathrm{H}_{11} \mathrm{NH}_{2}\right)\left(\mathrm{NH}_{3}\right)\right]$ (JM335) by thiols, Inorg. Chem. 39: 1728-1734.

[12] Beattie K, Basolo F (1967) Reduction of some platinum(IV) complexes with tris(bipyridine) chromium(II) ion.Inorg. Chem. 6: 2069-2073.

[13] Beattie K, Basolo F (1971) Two-electron inner-sphere reduction of chloropentaammine-platinum(IV) ion by aquochromium(II) ion. Inorg. Chem. 10: 486-491.

[14] Moodley KG, Nicol MJ (1977) Kinetics of the reduction of platinum(IV) by tin(II) and copper(I) in aqueous chloride solutions. J. Chem. Soc., Dalton Trans. 239-243.

[15] Sen Gupta KK, Das S, Sen Gupta S (1988)Kinetics and mechanism of the oxidation of thiosulphate by hexachloroplatinate(IV). Transition Met. Chem. 13: 155-159.

[16] Hassan RM, Kojima T, Fukutomi T (1982) Kinetics of the oxidation of uranium(IV) by hexachloroplatinate(IV) in aqueous solution. VI International symposium on solutesolute-solvent interactions. Japan, pp. 113.

[17] Sen Gupta KK, Begum BA, Ghosh SP (1998) Reactivities of osmium(VIII), iridium(IV) and platinum(IV) towards glycolaldehyde. Transition Met. Chem. 23: 295-299.

[18] Pal B, Sen Gupta KK (2000) Kinetics and mechanism of hexachloroplatinate(IV) reduction by some neutralized alphahydroxy acids in a carbonate-hydrogencarbonate buffer medium. Bull. Chem. Soc. Jpn. 73: 553-560.

[19] Pal B, Sen Gupta KK, Sen PK (2005) Oxidative cleavage of $\alpha$, $\beta$-unsaturated compounds by pentachlorohydroxoplatinate(IV) in alkaline medium. Transition Met. Chem. 30: 593-600.

[20] Sen Gupta KK, Sen PK, Sen Gupta S (1977) Kinetics of oxidation of hydrazinium ion by platinum(IV).Inorg. Chem. 16: 1396-1399.

[21] Sen Gupta KK, Sen PK (1977) Kinetics of the oxidation of hydroxylamine by platinum(IV). J. Inorg. Nucl. Chem. 39: $1651-1653$.

[22] Fawzy A (2015) Palladium(II)-catalyzed oxidation of Ltryptophan by hexacyanoferrate(III) in perchloric acid medium: a kinetic and mechanistic approach. J. Chem. Sci.In press.

[23] Fawzy A (2014) Influence of copper(II) catalyst on the oxidation of L-histidine by platinum(IV) in alkaline medium: a kinetic and mechanistic study. Transition Met. Chem. 39: 567-576.

[24] Fawzy A (2015) Kinetics and mechanistic approach to the oxidative behavior of biological anticancer platinum(IV) complex towards L-asparagine in acid medium and the effect of copper(II) catalyst. Int. J. Chem. Kinet. 47: 1-12.

[25] Fawzy A, Asghar BH (2015) Kinetics and mechanism of uncatalyzed and silver(I)-catalyzed oxidation of L-histidine by hexachloroplatinate(IV) in acid medium, Transition Met. Chem. 40: 287-295. 
[26] Asghar BH, Altass HM, Fawzy A (2015) Transition metal ions-catalyzed oxidation of L-asparagine by platinum(IV) in acid medium: akinetic and mechanistic study. Transition Met. Chem., 40: 587-594.

[27] Fawzy A, Zaafarany IA (2015) Kinetic and Mechanistic Investigation on the Zirconium(IV)-Catalyzed Oxidation of LHistidine by Hexachloroplatinate(IV) in Acid Medium. Chem. Sci. Rev. Lett., 4: 608-618.

[28] Fawzy A, Zaafarany IA (2015) Mechanistic investigation of copper(II)-catalyzed oxidation of L-asparagine by hexachloroplatinate(IV) in aqueous alkaline medium: a kinetic approach.J. Multidisc. Eng. Sci. Technol. 2: 1038-1045.

[29] Asghar BH, Altass HM, Fawzy A (2016) Silver(I)-catalysis of oxidative deamination and decarboxylation of L-asparagine and L-histidine by platinum(IV) in perchloric acid solutions: acomparative kinetics study. J. Env. Chem. Eng. 4: 617-623.

[30] Choi S, Filotto C, Bisanzo M, Delaney S, Lagasee D, Whitworth JL, Jusko A, Li C, Wood NA, Willingham J, Schwenker A, Spaulding K (1988) Reduction and anticancer activity of platinum(IV) complexes. Inorg. Chem. 37: 25002504.

[31] Fawzy A, Ashour SS, Musleh MA (2014) Base-catalyzed oxidation of L-asparagine by alkaline permanganate and the effect of alkali-metal ion catalysts: Kinetics and mechanistic approach. React. Kinet.Mech. Catal. 111: 443-460.

[32] Shukla R, Upadhyay SK (2008) Non-ionic micellar inhibition on the rate of oxidation of L-histidine by alkaline hexacyanoferrate(III). Indian J. Chem. 47A: 551-555.

[33] Georgieva M, Andonovski B (2003) Determination of platinum(IV) by UV spectrophotometry, Anal. Bioanal. Chem. 375: 836-839.

[34] Vogel AI (1973) Text book of practical organic chemistry, $3^{\text {rd }}$ ed., ELBS Longman, London, 1973, p. 332 and 679.

[35] Feigl F (1957) Spot Tests in Organic Analysis, Elsevier, New York, NY, USA.
[36] Fawzy A, Altass HM (2016) Ruthenium(III)-catalyzed oxidation of alginate and pectate biopolymers by chromic acid in aqueous perchlorate solutions: A comparative kinetic study. Transition Met. Chem. 41: 115-124.

[37] Griffith WP (1967) The chemistry of rare patinum metals, Interscience Publishers pp. 141.

[38] Kramer J, Koch KR (2006) ${ }^{195} \mathrm{Pt}$ NMR Study of the speciation and preferential extraction of Pt(IV)-mixed halide complexes by diethylenetriamine-modified silica-based anion exchangers, Inorg. Chem. 45: 7843-7855.

[39] Mason WR (1972) Platinum(II)-catalyzed substitutions of platinum(IV) complexes. Coord. Chem. Rev.7: 241-255.

[40] Hassan RM, Kojima T, Fukutomi T (1982) Kinetics of the oxidation of uranium(IV) by hexachloroplatinate(IV) in aqueous solution. VI International symposium on solutesolute-solvent interactions. Japan, pp. 113.

[41] Amis ES (1966) Solvent Effect on Reaction Rates and Mechanism, Academic Press, New York, pp. 28.

[42] Frost AA, Person RG (1970) Kinetics and mechanism, Wiley Eastern, New Delhi, pp. 147.

[43] Rochester CH (1971) Progress in Reaction Kinetics. Pergamon Press, Oxford, 1971, pp. 145.

[44] Laidler K (1965) Chemical Kinetics. McGraw-Hill, New York.

[45] Michaelis L, Menten ML (1913) The kinetics of invertase action. Biochem Z 49: 333-369.

[46] Hicks KW, Toppen DL, Linck RG (1972) Inner-sphere electron-transfer reactions of vanadium(II) with azidoamine complexes of cobalt(III). InorgChem11: 310-315.

[47] Weissberger A (1974) In Investigation of Rates and Mechanism of Reactions in Techniques of Chemistry, John Wiley \& Sons, pp. 421. 